\title{
ESTRATÉGIAS E TÁTICAS NA DOCÊNCIA DA DISCIPLINA ESTUDO DE PROBLEMAS BRASILEIROS DURANTE A DITADURA CIVIL-MILITAR NA UNIVERSIDADE FEDERAL DO PARANÁ (1971-1984)
}

\author{
STRATEGIES AND TACTICS IN THE TEACHING OF THE SUBJECT STUDY OF \\ BRAZILIAN PROBLEMS DURING THE CIVIL-MILITARY DICTATORSHIP AT \\ THE FEDERAL UNIVERSITY OF PARANÁ (1971-1984)
}

Rosa Lydia Teixeira Corrêa ${ }^{1}$

Rudimar Gomes Bertotti ${ }^{2}$

\begin{abstract}
RESUMO: Neste artigo objetivou-se analisar o processo de docência da disciplina Estudo de Problemas Brasileiros (EPB), na Universidade Federal do Paraná (UFPR), durante a ditadura civil-militar. Instituída como uma versão da Educação Moral e Cívica para o ensino superior, a EPB constituía-se como um componente curricular de conteúdo doutrinário. A pesquisa contou com o uso de diferentes fontes primárias e secundárias, com destaque para fontes orais, que permitiram desvelar nuances do processo de docência da EPB na UFPR. Foram selecionados como categorias de análise nesse trabalho os conceitos de Estratégia e Tática explorados por Michel de Certeau na obra Invenção do Cotidiano. A partir dessas categorias investigou-se à docência dessa disciplina na UFPR com base nos depoimentos de ex-professores de EPB que lecionaram na instituição durante o período ditatorial. Por fim, a análise desvelou que a disciplina de EPB traçou contornos próprios nas salas de aula da UFPR. A partir da adoção de táticas por parte de seus exdocentes, a EPB traçou caminhos distintos do que seus legisladores previram, ao menos na UFPR.
\end{abstract}

Palavras-chave: Estudo de problemas brasileiros. Ditadura. Ensino superior. História da educação.

\begin{abstract}
This paper aimed at analyzing the teaching process of the subject Study of Brazilian Problems at the Federal University of Paraná during the civilmilitary dictatorship. It was instituted as a version of Moral and Civic Education for higher education, the EPB constituted as a curricular component of doctrinal content. The research counted on the use of different primary and secondary sources, with emphasis on oral sources, which allowed to reveal nuances of the teaching process of the EPB in UFPR. The concepts of Strategy and Tactics explored by Michel de Certeau in The Practice of Everyday Life were selected as categories of analysis in this work. From these categories the teaching of this subject in the UFPR was investigated based on the testimonies of EPB exprofessors which taught in the institution during the dictatorial period. Finally, the analysis revealed that EPB subject had its own outline in the UFPR classrooms.

\footnotetext{
${ }^{1}$ Professora do Programa de Pós-Graduação, Mestrado e Doutorado em Educação da Pontifícia Universidade Católica do Paraná (PUC-PR), é graduada em Pedagogia (UFPA). Mestrado em Educação (UNICAMP). Doutorado em História Econômica (USP).

2 Mestre em Educação pela Universidade Federal do Paraná (UFPR) e Doutorando em Educação pela Pontifícia Universidade Católica do Paraná (PUC-PR). Licenciado em História e Pedagogia.
} 
From the tatics adoption by its ex professors, EPB followed a distinctive path from what its legislator had previewed, at least at UFPR.

Keywords: Study of brazilian problems. Dictatorship. Higher education. History of education.

\section{Introdução}

Este trabalho apresenta os resultados de pesquisa da dissertação de mestrado desenvolvida junto ao PPGE da Universidade Federal do Paraná (UFPR), da linha de pesquisa História e Historiografia da Educação, que buscou analisar o processo de docência da disciplina Estudo de Problemas Brasileiros (EPB) na (UFPR), durante a ditadura civil-militar.

Nos últimos anos, as pesquisas historiográficas que abordam a Educação durante o período conhecido como ditadura civil-militar têm se mostrado bastante diversas, teórica e metodologicamente. As recentes pesquisas sobre o tema têm voltado seus olhares para novas possibilidades, novos objetos e novas perspectivas de se produzir História, permitindo "identificar os modos como, em diferentes lugares e momentos, uma determinada realidade social é construída, pensada, dada a ler." (CHARTIER, 1990, p. 16).

Nesse sentido, os pressupostos da História Cultural têm contribuído de forma precípua para a renovação das produções acadêmicas que se dedicam a História da Educação como campo temático de pesquisa. Educação compreendida como "[...] mediação, referência por meio da qual as relações na sociedade e na cultura são construídas de uma maneira e não de outra." (FARIA FILHO, 2000, p. 16). A aproximação da História da Educação com a História Cultural permitiu que a primeira pudesse se apropriar de novos procedimentos metodológicos, referenciais de análise e objetos de investigação que ampliaram de forma considerável o leque de possibilidades do campo.

A partir da década de 1990, a historiografia da Educação passou por um processo de reconfiguração do campo, surgindo assim novos interesses de pesquisa como as práticas de leitura e escrita, a formação dos professores, as práticas dos agentes educacionais, a construção do conhecimento escolar, entre outros. De acordo com as autoras Mirian Warde 
e Marta Carvalho (2000), houve uma troca do enfoque da História da Educação, que ao invés de investir em pesquisas relacionadas às ideias pedagógicas passou a privilegiar produções com foco nas práticas educacionais:

É assim que a antiga história das ideias pedagógicas - uma das zonas mais frequentadas pela produção historiográfica anterior - é reconfigurada, pois perde terreno o interesse pelo estudo de ideias desencarnadas da materialidade dos dispositivos que as põem em circulação e das práticas dos agentes que as produzem ou que se apropriam delas. É assim também que começa a se configurar o campo de uma história cultural dos saberes pedagógicos, interessada na materialidade dos processos de produção, circulação, imposição e apropriação desses saberes (WARDE; CARVALHO, 2000).

Esse deslocamento da pesquisa historiográfica educacional permitiu apropriar-se de proposições de autores como Roger Chartier e Michel de Certeau, teóricos que com suas postulações e conceitos fornecem um instrumental teórico-metodológico que pode contribuir de forma profícua para as pesquisas relacionadas à História da Educação. Conforme mencionado anteriormente, esses autores já vêm contribuindo há certo tempo com o campo, e como destaca Faria Filho (2005, p. 7), o que é perceptível atualmente é uma nova forma de apropriação de suas proposições, "[...] têm sido feitas novas perguntas, a velhos objetos, antigos autores/interlocutores têm sido lidos de forma a ajudarem a entender a educação."

Nesse contexto, os conceitos de estratégia e tática explorados por Michel de Certeau na obra "Invenção do Cotidiano" (1994), foram selecionados como categorias de análise nesse trabalho sob o propósito de investigar a docência da disciplina Estudo de Problemas Brasileiros (EPB), durante a ditadura civil-militar, a partir dos depoimentos de ex-professores de EPB do período.

Com uma teoria que contrapunha os esclarecimentos acerca da noção de dominação disseminada por teóricos estruturalistas, Michel de Certeau (1994) concebeu um conjunto de conceitos que permitiu enxergar diferentes formas de resistência às estruturas de dominação social. Cabe 
ressaltar que essas formas de resistir, denominadas por Certeau como táticas, só se manifestavam de acordo com sua teoria frente à materialização de alguma estratégia, que o autor conceituou como:

[...] ações que, graças ao postulado de um lugar de poder (a propriedade de um próprio), elaboram lugares teóricos (sistemas e discursos totalizantes), capazes de articular um conjunto de lugares físicos onde as forças se distribuem. Elas combinam esses três tipos de lugar e visam dominá-los uns pelos outros (CERTEAU, 1994, p. 102).

Nesse sentido, a estratégia postula um lugar suscetível de ser circunscrito como algo próprio e ser a base de onde se podem gerir as relações com uma exterioridade de alvos ou ameaças como, por exemplo, a administração de uma instituição de ensino superior que busca racionalizar uma estratégia para se distinguir como espaço de querer e poder (CERTEAU, 1994).

Conforme mencionado, toda estratégia produz uma tática correspondente, que Michel de Certeau (1994, p. 100) definiu como:

[...] a ação calculada que é determinada pela ausência de um próprio. Então nenhuma delimitação de fora lhe fornece a condição de autonomia. A tática não tem por lugar senão o do outro. E por isso deve jogar com o terreno que lhe é imposto tal como o organiza a lei de uma força estranha. Não tem meios para se manter em si mesma, a distância, numa posição recuada, de previsão e de convocação própria: a tática é movimento "dentro do campo de visão do inimigo", [...] e no espaço por ele controlado.

Assim, pode-se pensar na manifestação de táticas, como formas de resistência frente a implantação de uma estrutura de dominação como, por exemplo, o estabelecimento de uma disciplina doutrinária como o Estudo de Problemas Brasileiros (versão da Educação Moral e Cívica para o ensino superior), componente curricular criado pelos militares durante a ditadura civil-militar e instituído como obrigatório para todos os cursos de graduação e pós-graduação do Brasil no período.

Para compreender como se manifestaram essas relações, esse trabalho elencou como objeto de pesquisa o processo de docência da disciplina Estudo de Problemas Brasileiros, na Universidade Federal do 
Paraná, durante o período conhecido como ditadura civil-militar. Com o objetivo de compreender de forma mais contundente a manifestação de estratégias e táticas que permearam o processo de docência da disciplina Estudo de Problemas Brasileiros, essa pesquisa contou com depoimentos de ex-docentes dessa disciplina.

O objetivo principal desse trabalho foi investigar, a partir dos conceitos de estratégia e tática, o desenvolvimento da docência da disciplina Estudo de Problemas Brasileiros na Universidade Federal do Paraná, respondendo dessa forma se as finalidades dessa disciplina se concretizaram ou não, e como, no âmbito dessa instituição de ensino.

\section{Cotidiano e práticas de ex-docentes de EPB da UFPR}

O uso de fontes orais permite compreender particularidades do passado não registradas de forma escrita. Considerando a dificuldade em reconstruir o cotidiano e a prática de professores de EPB na UFPR, durante a ditadura civil-militar apenas com base em documentos emitidos pela Universidade e pela Coordenação $\mathrm{Geral}^{3}$ da disciplina, as fontes orais que alicerçaram essa pesquisa permitiram construir análises que foram ao encontro do objetivo aqui previamente estabelecido.

Um dos questionamentos que surgiram durante o desenvolvimento da pesquisa foi a respeito da organização do ensino da disciplina de EPB na Universidade. De acordo com o Parecer n. 94/71, os docentes que lecionavam a EPB deveriam seguir um programa de ensino que se encontrava anexo a essa legislação, conforme descrito no Quadro 1.

\footnotetext{
${ }^{3}$ A criação de um órgão para coordenar a disciplina de EPB na UFPR, bem como o cargo de coordenador para administrar seu ensino, foram prescrições do Parecer CFE n. 94/71, medida legal responsável pela normatização do ensino da disciplina de EPB.
} 
Quadro 1 - Programa de Ensino de EPB Anexo ao Parecer n. 94/71

\begin{tabular}{|c|c|}
\hline \multicolumn{2}{|c|}{ PROGRAMA DE ESTUDO DE PROBLEMAS BRASILEIROS } \\
\hline $\begin{array}{l}\text { UNIDADE I } \\
\text { Panorama Geral da Realidade } \\
\text { Brasileira }\end{array}$ & $\begin{array}{l}\text { 1. Características gerais da geopolítica e } \\
\text { geoeconomia nacional. } \\
\text { 2. } 2 \text {. O homem brasileiro: formação étnica e } \\
\text { cultural; traços característicos; pirâmide etária; } \\
\text { situação demográfica. } \\
\text { 3. 3. As instituições sociais, políticas e econômicas. } \\
\text { 4. 4. O comportamento social; ação comunitária; } \\
\text { ética individual; profissional e social. }\end{array}$ \\
\hline $\begin{array}{l}\text { UNIDADE II } \\
\text { Problemas Morfológicos }\end{array}$ & $\begin{array}{l}\text { 1. As estruturas econômicas: análise do sistema } \\
\text { econômico brasileiro. } \\
\text { 2. As estruturas sociais. } \\
\text { 3. As estruturas políticas e as características da } \\
\text { democracia no Brasil. } \\
\text { 4. A estrutura dos poderes Executivo, Legislativo e } \\
\text { Judiciário. }\end{array}$ \\
\hline $\begin{array}{l}\text { UNIDADE III } \\
\text { Problemas de Desenvolvimento } \\
\text { Econômico }\end{array}$ & $\begin{array}{l}\text { 1. A riqueza nacional do solo, subsolo e fundo do } \\
\text { mar; Petróleo e Siderurgia. } \\
\text { 2. Povoamento e preservação do solo. } \\
\text { 3. A Amazônia e seus problemas. } \\
\text { 4. O nordeste e seus problemas. } \\
\text { 5. Os transportes e a economia. } \\
\text { 6. Desenvolvimento agrícola e pecuário; Reforma } \\
\text { Agrária. } \\
\text { 7. Problema energético. } \\
\text { 8. Desenvolvimento industrial. } \\
\text { 9. Comércio interno e internacional. } \\
\text { 10. Disparidades regionais e desequilíbrios sócio- } \\
\text { econômicos; Organismos regionais. } \\
\text { 11. O desenvolvimento econômico e a integração } \\
\text { econômica setorial e nacional. } \\
\text { 12. Política monetária, creditícia e fiscal. } \\
\text { 13. Planejamento econômico. } \\
\text { 14. Trabalho e previdência social. } \\
\text { 15. Mercado de capitais. }\end{array}$ \\
\hline $\begin{array}{l}\text { UNIDADE IV } \\
\text { Problemas Sócio-Econômicos }\end{array}$ & $\begin{array}{l}\text { 1. Habitação } \\
\text { 2. Saúde: prevenção, assistência médica e } \\
\text { reabilitação. Saneamento básico e erradicação das } \\
\text { endemias. } \\
\text { 3. Educação: diagnóstico e soluções. } \\
\text { 4. Comunicação social e difusão cultural. } \\
\text { 5. A ciência, a tecnologia e seu papel no } \\
\text { desenvolvimento. } \\
\text { 6. As artes e sua função cultural. } \\
\text { 7. Urbanização. } \\
\text { 8. Empresa - sua função social e sua participação } \\
\text { no desenvolvimento. } \\
\text { 9. As Forças Armadas no processo sócio-econômico } \\
\text { do Brasil. }\end{array}$ \\
\hline
\end{tabular}




\begin{tabular}{|l|l|}
\hline UNIDADE V & 1. Filosofias e Ideologias Políticas. \\
Problemas Políticos & 2. O Poder Nacional: suas expressões. \\
& 3. Representação Popular. \\
& 4. Partidos Políticos: organização e funcionamento. \\
& 5. Evolução Política Nacional. \\
& 6. Problemas Políticos: a ocupação do solo e os \\
& limites territoriais. \\
& 7. Política Econômica. \\
& 8. Política Social. \\
& 9. Política Externa. \\
& 10. Organismos políticos e internacionais: ONU e \\
& OEA. \\
\hline UNIDADE VI & 1. Segurança externa e interna - Responsabilidade \\
& do cidadão. \\
& 2. Guerra revolucionária. \\
& 3. As Forças Armadas - Marinha, Exército e \\
& Aeronáutica. \\
& 4. Estabelecimento de uma doutrina e formulação \\
de uma política de segurança nacional - Conselho \\
de Segurança Nacional - Estado Maior das Forças \\
Armadas - Escola Superior de Guerra.
\end{tabular}

Fonte: PARECER N. 94 DO CONSELHO FEDERAL DE EDUCAÇÃO (1971).

Na UFPR, alguns professores de EPB seguiram as orientações que constavam nesse documento. Para o professor Alceu Rolkoski ${ }^{4}$, a EPB:

[...] era organizada através de um programa pré-elaborado, vindo de Brasília e com pequenas adaptações aos problemas da cidade em termos de pobreza, em termos de educação, em termos de assistência aos menores e assim se adaptava entre o programa oficial e a problemática local.

Segundo o ex-coordenador da disciplina, professor Maury Rodrigues da $\mathrm{Cruz}^{5}$, os programas de ensino de EPB, instituídos pelo MEC, eram apresentados aos professores e adequados de acordo com as reais necessidades da população. "Então eu instruía os professores para mostrar a realidade, nós sempre íamos fazer visita ao Asilo São Vicente de Paula, em hospitais, casas de saúde, a gente derivava um pouco e ficava em torno da promoção da pessoa." 6

\footnotetext{
${ }^{4}$ Entrevista concedida em 2014, por Alceu Rolskoski.

${ }^{5}$ Maury Rodrigues da Cruz foi Coordenador da disciplina Estudo de Problemas Brasileiros na UFPR, entre o início da década de 1970 e 1984, último ano de vigência da ditadura civilmilitar no Brasil.

${ }^{6}$ Entrevista concedida em 2013, por Maury Rodrigues da Cruz.
} 
Esse tipo de ação também ocorria em outros projetos estratégicos ligados à Educação e alinhados à Doutrina de Segurança Nacional e Desenvolvimento $^{7}$ (DSND) como o Projeto Rondon, objeto de investigação de Vieira (2014), apoiada em Rocha (1986, p. 116), no qual "[...] O universitário podia conhecer outras realidades, comprometendo-se com o governo na solução de problemas em áreas estratégicas de seu interesse, contribuindo para o desenvolvimento econômico do país." Nesse sentido, a ênfase nos problemas nacionais, por parte dos ex-docentes de EPB, denota uma adesão a uma política maior da DSND que visava incentivar a participação da juventude universitária no plano político-econômico nacional.

Conforme explicitado anteriormente, a disciplina de EPB possuía um programa de ensino previamente estabelecido no Parecer n. 94/71, e que foi utilizado na UFPR durante o período da ditadura. Em todos os depoimentos concedidos nessa pesquisa, os ex-docentes da disciplina afirmaram que conheciam o programa de ensino de EPB e que o utilizaram para ministrar suas aulas, com exceção do professor Luiz Nicolau Maeder Sunyé ${ }^{8}$, que afirmou não conhecer o programa de ensino, ministrando suas aulas por meio da discussão dos grandes problemas que afligiam o país.

Entretanto, a constatação de que a maioria dos professores de EPB conhecia o programa de ensino da disciplina não descarta uma apropriação singular dos conteúdos que deveriam ser ministrados nas aulas. Segundo Chartier (2001, p. 67):

[...] apropriação [...] consiste no que os indivíduos fazem com o que recebem, e que é uma forma de invenção, de criação e de produção desde o momento em que se apoderam dos textos ou dos objetos recebidos. Desta maneira, o conceito de apropriação pode misturar o controle e a invenção, pode articular a imposição de um sentido e a produção de novos sentidos.

\footnotetext{
${ }^{7} \mathrm{Na}$ acepção de Gonçalves (2011, p. 8), ao refletir sobre o desenvolvimento da Doutrina de Segurança Nacional e Desenvolvimento, a Educação contribuiria para o Desenvolvimento, tendo em vista que tornaria acessíveis à população, a cultura e o trabalho - no manual da Escola Superior de Guerra, destaca-se - a importância fundamental da educação do homem como investimento mais produtivo para o desenvolvimento", o que propiciaria a reformulação das estruturas do primeiro, segundo e terceiro graus por meio das Leis $5.540 / 68$ e $5.692 / 71$.

${ }^{8}$ Entrevista concedida em 2014, por Luis Nicolau Maeder Sunyé.
} 
Para o ex-docente de EPB, Wilciomar Voltaire Garcia, o programa de ensino foi um mero referencial para ministrar a disciplina. Esse docente não se atinha ao programa afirmando que não havia nenhum tipo de exigência para seguir os conteúdos previstos no documento. Ainda, de acordo com esse professor, ao ministrar suas aulas de EPB, ele levava para a sala de aula livros que não constavam na bibliografia do programa de ensino da disciplina, como a obra "As veias abertas da América Latina", de Eduardo Galeano, "[...] eu não me atinha ao programa...não era exigido, pelo menos na época que eu tive lá nunca me exigiram fazer isso ou aquilo. ${ }^{9}$

No depoimento da professora Maria de Lourdes Montenegro Holzmann também foi possível encontrar um distanciamento das prescrições do programa de ensino da disciplina de EPB na UFPR. A visão que essa ex-docente tinha sobre a EPB era bem diferente dos que defenderam a inclusão desse componente curricular nos currículos da Universidade. De acordo com a professora, a EPB:

[...] era uma disciplina do medo... porque era em pleno período da ditadura, então nós éramos normalmente chamados pelo reitor para que ele soubesse o que nós íamos dar...e eu tive muita sorte porque o reitor da universidade era o Flávio Suplicy Lacerda que havia sido um dos assinantes do Ato Institucional número 5 e ele era meu primo... então jamais passou pela cabeça dele que eu fosse para sala de aula para fazer uma revolução...o que eu tentava mostrar para os alunos era a importância de você ter oportunidade de estudar e que isso servisse não só para você mas para o país inteiro...então eu lembrei bem que eu dei aula de EPB para o povo de engenharia e de arquitetura, sabe, era tanta gente, eu dava aula na reitoria ali no anfiteatro. Eu sempre procurei, dentro da minha disciplina mostrar a realidade brasileira para os meus alunos...então quando ia dar aula para o pessoal da medicina eu ia no hospital das clínicas...eles lembram até hoje... e eu levava alguma favelada e ela contava como tinha sido o parto dela sem médico, sem medicamento, sem nada na favela... os meninos começaram a discutir a realidade da pobreza, da miséria com aquela gente, para que eles melhorassem, eu tenho horror de pensar que um profissional liberal de alto nível não sabe para quem tá trabalhando, então...eu tinha esse compromisso ${ }^{10}$.

\footnotetext{
${ }^{9}$ Entrevista concedida em 2014 por Wilciomar Voltaire Garcia.

${ }^{10}$ Entrevista concedida em 2014 por Maria Lourdes Montenegro Holzmann.
} 
A partir dessa perspectiva, é interessante analisar como a professora Maria de Lourdes Montenegro Holzmann operava no planejamento de suas aulas para as turmas de EPB na UFPR. De acordo com a professora:

Eu procurava saber, por exemplo, se eu tinha que dar aula para engenharia, ver qual era o programa de engenharia, porque nós dávamos aulas para todos os cursos... eu tive sorte porque estava ao mesmo tempo no Banco Nacional da Habitação, então era fácil para mim isso... eu sempre procurei preparar as aulas com base em princípios que são meus... não eram da revolução... eram princípios meus.

Entretanto, o emprego da terminologia revolução em vez de golpe no depoimento dessa ex-docente de EPB, bem como sua afinidade com um dos mais emblemáticos reitores no período da ditadura civil-militar, denota algumas incongruências em suas declarações que, por diversas vezes, enuncia críticas ao caráter da disciplina.

Segundo essa professora, os critérios que embasavam o planejamento das aulas de EPB, concentravam-se nas especificidades das turmas dos diferentes cursos de graduação em que ela era incumbida de lecionar a disciplina. A bibliografia que fundamentava o programa de ensino de EPB não foi utilizada por essa professora, que optou pela adoção de outros referenciais que não constavam no programa como, por exemplo, as obras do sociólogo Florestan Fernandes. Não obstante essa ex-docente de EPB tenha ignorado a bibliografia do programa de ensino, faz-se necessário destacar que as unidades do programa foram seguidas por essa profissional, "[...] nós seguíamos esse programa, mas você tinha liberdade de usá-lo da maneira correta" (HOLZMANN, 2014).

A partir desse contexto, é possível observar que o uso do programa de ensino da disciplina de EPB como referencial para ministrar as aulas foi quase unânime entre seus docentes. Entretanto, as adaptações ao programa, bem como a autonomia para flexibilizar seus conteúdos, também foram consensuais nesse processo, "[...] tornando visíveis as resistências do homem comum, resistências que fundam micro liberdades e deslocam as fronteiras de dominação" (DURAN, 2012, p. 44).

Além das aulas convencionais em sala, os ex-docentes da disciplina de EPB também ministravam suas aulas em instituições públicas e privadas 
como asilos, hospitais e orfanatos com o propósito de apresentar e discutir os problemas nacionais. De acordo com o professor Alceu Rolkoski:

[...] os trabalhos dos alunos eram...dirigidos para que eles visitassem casas de caridade, instituto dos cegos, lar dos meninos, instituto médico legal...temas assim, digamos hoje chamados transversais... dentro de um contexto onde existia o problema do estado do Paraná...sobre o índice de prostituição, de menores abandonados, então se fazia esse tipo de trabalho, se discutia ali possíveis soluções.

Segundo o professor Maury Rodrigues da Cruz, era proposto aos docentes realizar essas aulas de campo ao menos duas vezes por semestre. No seu depoimento, o ex-coordenador da EPB na UFPR, enfatiza que a partir dessas aulas surgiu uma preocupação com o mobiliário urbano da cidade, os alunos passaram a "[...] conhecer instituições importantes como o cemitério...obras de arte...transporte coletivo...vultos eméritos do Paraná." Segundo Vieira (2014), esse tipo de atividade já era mencionada na Lei 5.540/68 "[...] como oportunidade de participação discente em programas de melhoria das condições de vida da comunidade e no processo geral de desenvolvimento da nação, o que remete à doutrina difundida pela ESG" ( $p$. 76). Além disso, a autora enfatiza que:

A Lei apresenta também em seu texto a difusão cultural e o estímulo cívico/patriótico com o intuito de responsabilizar o cidadão no processo de desenvolvimento da nação, por meio da prestação de serviço comunitário o que pode ser um indicativo da presença do mecanismo assistencialista no âmbito de sua formulação (VIEIRA, 2014, p. 76).

Nos programas de ensino de EPB havia menção às atividades didáticas, que deveriam ser desenvolvidas durante o semestre, estando inclusas as visitas às instituições públicas e privadas. Essas ações compunham o processo de ensino e aprendizagem da disciplina e permeavam as práticas dos docentes de EPB do período. Entretanto, ao analisar a conduta dos ex-docentes da disciplina de EPB e sua relação com o programa de ensino desse componente curricular, surgiu um questionamento acerca da concepção que esses professores tinham sobre o caráter da EPB. De acordo com a percepção desses professores, a EPB seria 
uma disciplina como qualquer outra? Ou uma disciplina doutrinária, conforme alguns textos das medidas legais que a regulamentaram a denominavam?

De acordo com Bertotti (2015), o Decreto que instituiu a obrigatoriedade do ensino da disciplina de EPB nas universidades brasileiras foi fundamentado nos princípios da DSND. A influência desses princípios pôde ser observada nos textos das medidas legais que regulamentaram a disciplina. Na análise dos Decretos n. 869/69 e n. 68.605/71, foram encontradas durante seis oportunidades a menção direta à disciplina como doutrina.

Compreende-se, portanto, que o âmbito educacional foi alvo de especial atenção durante a ditadura civil-militar, pois encontra-se presente nas diretrizes doutrinárias da ESG como manobras e estratégias da Ação Psicológica, que através de medidas educacionais [...] tiveram grande importância na formação de mão-de-obra com intenção de impulsionar o crescimento econômico e o desenvolvimento do país (VIEIRA, 2014, p. 66).

Dessa forma, era difícil não estabelecer um vínculo entre a EPB e seu caráter doutrinário, embora o professor Maury Rodrigues da Cruz tentasse descaracterizar essa relação argumentando que não existiu doutrinação na prática docente dos professores de EPB, "[...] a título de doutrinação não houve, a título de imposições, de maneira nenhuma...era uma disciplina igual as outras, com temáticas sociológicas... sempre foi isso."

Entretanto, segundo artigo publicado na Revista Educação, periódico sob responsabilidade do MEC, a EPB não deveria ser lecionada fundamentando-se apenas em temáticas sociológicas ou em disciplinas que compunham as ciências humanas. Segundo o texto do professor Magdaleno Girão Barroso (1978, p. 30):

Em principio, não se pode ministrar um curso de Estudo de Problemas Brasileiros sem definir a natureza dessa disciplina. Trata-se de aspecto polêmico. Muitos entendem que o seu conteúdo, destinado a estudantes do ensino superior, não comporta implicações - que a lei francamente lhe atribui com a Educação Moral e Cívica, e, aliás, não raro, o identificam com outras matérias da área de ciências humanas ou mesmo de ciências físicas e naturais. Preciso no entanto se saiba: na forma da legislação que rege a espécie 
(Decreto-Lei no 869/69 e Decreto no 68.065/71), Estudo de Problemas Brasileiros não é senão o nome que nas universidades adquire a Educação Moral e Cívica, instituída obrigatoriamente pela citada legislação em todos os graus e modalidades do nosso sistema geral de ensino.

Por outro lado, nem todos os professores da disciplina compartilhavam da concepção do ex-coordenador da EPB na UFPR. Para a professora Maria Lourdes Montenegro Holzmann, a EPB:

[...] veio como uma doutrina dos milicos... os militares queriam que nós professores ensinássemos o que eles achavam correto... não sei se todos fizeram isso, eu nunca fiz, eu nunca obedeci, pra mim era mais importante que quando os alunos saíssem de lá, eles soubessem que eu era uma mulher séria, que tentava passar pra eles o que eu tinha aprendido e mostrar os caminhos para que eles procurassem...e o que os militares diziam não me interessava.

A conduta dessa ex-docente de EPB vai de encontro as finalidades da disciplina, mas será que realmente essa professora agiu assim? Considerando a existência de órgãos como a Assessoria Especial de Segurança e Informações ${ }^{11}$ (AESI) da UFPR e outros instrumentos de fiscalização, é difícil atestar que comportamentos dessa natureza passassem despercebidos. Nesse contexto, a citação de Diana Vidal (1998) pode subsidiar a compreensão desse tipo de reminiscência:

Ao elaborar seu depoimento, nem o (a) depoente revivia o passado, resgatando intacta a memória de um acontecimento - a integridade de um momento -, nem recuperava as emoções, os sentimentos e os saberes que aquele instante lhe provocou originalmente - como ressurgidos pelo gosto da pequena Madalena -, apenas materializava em discurso suas reminiscências, construindo reelaborações no presente sobre o passado. O ontem não renascia na narrativa memorialística, mas era produzido pelo olhar que de hoje Ihe lançava o (a) rememorador (a), crivado por influências várias, que cabia ao (à) historiador (a) decifrar: imagens veiculadas pelos meios de comunicação de massa ou pela própria historiografia, ou processos psicológicos de auto-afirmação ou negação, dentre outras (VIDAL, 1998, p. 10).

${ }^{11}$ Assessoria Especial de Segurança e Informações (AESI) era um órgão de controle e fiscalização que selecionava os professores de EPB indicando se estavam aptos ou não para o exercício da docência dessa disciplina na Universidade. 
Contudo, o depoimento da ex-docente da disciplina de EPB permite compreender que o consentimento do caráter doutrinário da disciplina não impedia seus docentes de apropriarem-se de condutas táticas que transfiguravam a natureza desse componente curricular. Não obstante o excoordenador da disciplina Maury Rodrigues da Cruz acreditasse nos benefícios da EPB, alguns elementos que vieram à tona no decorrer da pesquisa apontam que esse professor também manifestou condutas táticas quando das imposições doutrinárias da legislação que normatizava a disciplina. A plena autonomia de professores de EPB ao ministrarem suas aulas, e o caráter humanista que esse professor tentou imprimir à disciplina, indicam que na UFPR, as práticas relacionadas à docência da EPB assumiram um formato diferente do que o texto da legislação que a criou previa. Essa constatação permite observar dois aspectos que permearam o processo de implantação e desenvolvimento da disciplina de EPB. O primeiro permite concluir que os agentes ligados à implantação da disciplina na UFPR, acataram as prescrições legais da legislação que estabelecia esse componente curricular na Universidade, inclusive adotando, nos programas de ensino que fundamentavam a docência dessa disciplina, o modelo anexo ao Parecer n. 94/71. O segundo enseja afirmar que, embora a Coordenação Geral de EPB tenha estabelecido os programas de ensino conforme o texto da lei, os agentes ligados à docência desse componente curricular subverteram as prescrições dos programas de ensino, adotando condutas que muitas vezes desvirtuavam o caráter doutrinário da disciplina. Nesse sentido, é importante frisar que a resistência ao caráter doutrinário dessa disciplina compreendeu um limite, afinal, os indícios de adequações ao programa de ensino da EPB coexistiram com a permanência de um programa de ensino idêntico ao proposto pelo Parecer CFE n. 94/71: "[...] Em síntese, as estratégias são capazes de produzir e impor. Já as táticas só permitem utilizar, manipular e alterar algo" (DURAN, 2012, p. 45). Segundo o professor Wilciomar Voltaire Garcia, a coordenação do professor Maury Rodrigues da Cruz foi muito humana, uma gestão equilibrada, sem nenhum tipo de pressão para seguir quaisquer orientações doutrinárias. 


\section{Considerações finais}

Considerando os conceitos de estratégia e tática de Michel de Certeau como referenciais de análise para a compreensão do desenvolvimento da docência da disciplina Estudo de Problemas Brasileiros, criada na UFPR, durante a ditadura civil-militar, foi possível apreender a partir das memórias de ex-docentes dessa disciplina que o caráter doutrinário outorgado à EPB não foi integralmente reproduzido durante seu desenvolvimento na Universidade. Não obstante o Coordenador Geral da EPB na UFPR, fosse um defensor dos princípios morais e cívicos como elementos essenciais para a formação dos jovens do país, aparentemente sua concepção particular desses preceitos divergiu dos princípios que se alinhavam à DSND. De acordo com os apontamentos da pesquisa, o caráter doutrinário incutido à disciplina dependia quase que exclusivamente da ação docente em si, do que de medidas legais que enfatizassem orientações doutrinárias. Contudo, condutas táticas demandam um lugar, representado nessa pesquisa pela Coordenação Geral de EPB e a sala de aula. Nesse sentido, não é possível pensar na manifestação de táticas apenas pela atuação do corpo docente, sem, no entanto, considerar as relações estabelecidas entre esses agentes e um lugar.

Os espaços abertos pelas táticas são, na verdade, a prática de um lugar, um lugar submetido à organização dinâmica e complexa. As táticas não podem ser pensadas sem um lugar, da mesma forma que a fala não pode ser pensada sem língua, ou enunciado sem enunciação (JOSGRILBERG, 2005, p. 71).

Esse trabalho permitiu vislumbrar as singularidades com que exdocentes da disciplina de EPB se apropriaram das orientações provenientes das medidas legais que normatizaram essa disciplina na UFPR. Delimitando - caráter doutrinário da disciplina à ênfase na temática dos grandes problemas nacionais, foi possível observar que a EPB traçou contornos próprios nas salas de aula da UFPR. Por meio de adaptações da bibliografia e a resiliência dos professores, essa disciplina traçou caminhos distintos do que seus legisladores previram, ao menos na UFPR. A adoção de táticas 
frente às estratégias doutrinárias do regime foi uma prática comum de parte do corpo docente responsável pelo ensino da disciplina de EPB.

Além disso, esse trabalho foi parcialmente construído por meio de fontes orais, que permitiram encontrar perspectivas muito além das fontes oficiais. Sem os subsídios das memórias dos ex-docentes da disciplina de EPB na UFPR, seria impossível encontrar respostas a questões relacionadas às práticas e ao cotidiano dos profissionais que lecionaram a EPB durante a ditadura civil-militar na UFPR.

\section{Referências}

BARROSO, Magdaleno Girão. Compreensão da disciplina estudo de problemas brasileiros. Revista Educação, ano 7, n. 27, p. 29-34, 1978.

BERTOTTI, Rudimar Gomes. Caráter, amor à pátria e obediência a lei: disciplina Estudo de Problemas Brasileiros. 2015. 194 f. Dissertação (Mestrado em Educação) - Universidade Federal do Paraná, Curitiba, 2015.

CERTEAU, M. A invenção do cotidiano. 4. ed. Petrópolis, RJ: Vozes, 1994. v. 1: Artes de fazer.

CHARTIER, Roger. A história cultural: entre práticas e representações. Lisboa: Diefel; Rio de Janeiro: Bertrand, 1990.

CHARTIER, Roger. Cultura escrita, literatura e história: conversas de Roger Chartier com Carlos A. Anaya, Jesús A. Rosique, Daniel Goldin e Antonio Saborit. Porto Alegre: Artmed Editora, 2001.

DURAN, Marília Claret Geraes. Uma leitura do cotidiano escolar com Michel de Certeau. International Studies on Law and Education, São Paulo, v. 12, p. 43-48, 2012.

FARIA FILHO, Luciano Mendes (org.). Pensadores sociais e história da educação. Belo Horizonte: Autêntica, 2005.

FARIA FILHO, Luciano Mendes. Instrução elementar no século XIX. In: LOPES, Eliana Marta Teixeira; FARIA FILHO, Luciano Mendes; VEIGA, Cynthia Greive (org.). 500 anos de educação no Brasil. Belo Horizonte: Autêntica, 2000.

GONÇALVES, Nadia G. Doutrina de segurança nacional e desenvolvimento na ditadura civil-militar: estratégias e a educação. In: SIMPÓSIO NACIONAL DE HISTÓRIA - ANPUH, 26., 2011, São Paulo. Anais [...]. São Paulo: ANPUH, 2011.

JOSGRILBERG, Fabio B. Cotidiano e invenção: os espaços de Michel de Certeau. São Paulo: Escrituras Editora, 2005. 
ROCHA, Roberto Mauro Gurgel. Extensão universitária: comunicação ou domesticação? São Paulo: Cortez: Autores Associados: Universidade Federal do Ceará, 1986.

VIDAL, Diana Gonçalves. A fonte oral e a pesquisa em história da educação: algumas considerações. Educação em Revista, Belo Horizonte, n. 27, p. 716, jul. 1998.

VIEIRA, Carina Silva. Extensão Universitária: concepções presentes na formalização e em propostas e práticas desenvolvidas na Universidade Federal do Paraná (1968-1987). 2014. Dissertação (Mestrado), Universidade Federal do Paraná, Curitiba, 2014.

WARDE, Miriam Jorge; CARVALHO, Marta Maria Chagas de. Política e cultura na produção da História da Educação no Brasil. Contemporaneidade e Educação, Rio de Janeiro, v. 5, n. 7, p. 9-33, 2000. 